\title{
Çocuklarda Yeşil Çay Kullanımının Dental ve Periodontal Sağllı̆̆a Etkileri
}

\author{
Effects of Green Tea Use on Dental and Periodontal Health in Children
}

Handan Vural, Sacide Duman

(1)

İnönü Üniversitesi Diș Hekimliği Fakültesi Pedodonti Anabilim Dalı, Malatya, Türkiye

Correspondence:

Handan VURAL

İnönü Üniversitesi Diş Hekimliği Fakültesi Pedodonti Anabilim Dall, Malatya, Türkiye

e-mail: handan.yildar@gmail.com

\section{Abstract}

Oral hygiene is essential for prevention of dental caries and periodontal diseases. If mechanical cleaning cannot be performed, mouthwashes, which have antimicrobial, anti-inflammatory and antiplaque effects, are of great importance in providing oral hygiene. The healing effects of polyphenols in content of green tea, which is a common beverage, have been reported in many studies. Epigallocatechin-3-gallate (EGCG) is major polyphenol found in green tea. It is most biologically active with its antioxidant, antiinflammatory, antibacterial and anticarcinogenic properties.In this review, current literature information has been compiled dental and periodontal effects of green tea use in children. Green tea; Chlorhexidine etc. features such as wide age range in its use, mostly no side effects, no limited usage period, no harm in swallowing. are its main advantages over mouthwashes. Green tea, an easy-to-find, low-cost herb for oral healthy can be a beneficial agent.

Keywords: Child, Dentistry, Mouthwash, Green tea

Özet

Diş çürüğü ve periodontal hastalıkların önlenmesinde öncelikle iyi bir oral hijyen gereklidir. Antimikrobiyal, antienflamatuar ve antiplak özellikli gargaralar mekanik temizleme yapılamadığı durumlarda oral hijyen sağlamada büyük öneme sahiptir. Yaygın bulunan bir içecek olan yeşil çayın içeriğindeki polifenollerin iyileștirici etkileri birçok çalışmada bildirilmiştir. Epigallokateşin gallat (EGCG), yeşil çayda bulunan başlıca polifenoldür. Antioksidan, antienflamatuar, antibakteriyel ve antikanserojenik özellikleriyle biyolojik olarak en aktif olanıdır. Yeşil çayın ağız ve diş sağlığına etkilerine yönelik birçok çalışma yapılmıștır. Bu derlemede yeşil çayın çocuklarda kullanımının dental ve periodontal sağlığa etkileriyle ilgili güncel literatür bilgileri derlenmiştir. Kullanımında yaş aralığının geniş olması, çoğunlukla herhangi bir yan etkisinin olmaması, sınırlı kullanım süresinin olmaması, yutulmasında bir sakınca olmaması gibi özellikler yeşil çayın klorheksidin vb. gargaralara karşı başııca avantajlarıdır. Kolay bulunabilen, düşük maliyetli bir bitki olan yeşil çay sağlıklı bir ağız için faydalı bir ajan olabilir.

Anahtar Kelimeler: Çocuk, Diş Hekimliği, Gargara, Yeşil çay 


\section{Giriș}

Bitkiler, uygarlık tarihinin ilk zamanlarından beri hastalıkları tedavi etmekte yaygın olarak kullanılmıştır. 21. yüzyılda ekonomik, sosyal ve çevresel değişimlerle beraber bitkisel ürünlere ilgi giderek artmaktadır. Dünya Sağlık Örgütü'ne göre, dünya nüfusunun \%80'inden fazlası, temel sağlık ihtiyaçlarında başta bitkiler olmak üzere, geleneksel ilaçlara daha sık güvenmektedir (1). Uzun zamandır bitkiler ve doğal maddeler terapötik ilaç kaynağ1 olarak, ağrı kesici, ateş düşürücü, antimikrobiyal, antiinflamatuar, antikanser vb. özellikleriyle fitofarmakoljide kullanılmaktadır. Kurkumin, yüksük otu, aleo vera, tarçın, çemen otu, Yerbe Mate, tarhun, kekik, yeşil çay gibi pek çok bitkinin genel sağlığa olan katkıları bilimsel olarak kanıtlanmıştır (1).

Dental ve periodontal doku proflaksisinin en başında ağız hijyeni gelmektedir. Tek başına düzenli ve doğru fırçalamayla çürük ve periodontal hastalık insidansı ciddi düzeyde gerilemektedir. Ancak firçalamanın etkinliğinde firçadan macuna, firçalama süresinden firçalama tekniğine, kişinin motor becerisine kadar birçok faktör etkilidir. Özelikle çocuklarda, mental ya da bedensel engelli bireylerde temel firçalama etkililiğini sağlamak çok daha zordur. $\mathrm{Bu}$ durumda firçalamayla beraber yardımcı metotlar da önem kazanmaktadır. Kimyasal ajanlar, mekanik plak kontrolünün etkisini arttırmak için giderek daha fazla kullanılmaktadır. Doğal içerikli ağız sağlığı ürünlerinin kullanıma hazır ambalajlı olarak doğrudan tüketiciye sunulması, sentetik ürünlere kıyasla bitkisel/doğal ürünlere talebi arttırmıştır.

Günümüzdeki doğal olana karşı artan bu ilgi, bilimsel çalışmaların yol göstericiliğinde desteklenmeli ve denetlenmelidir. Çağdaş bilimsel çalışmalar, antik ve geleneksel tıbbın bilgilerinin doğruluğunu ve güvenilirliğini aydınlatırken, bilinen bitki ve karışımlarının farklı kullanım alanlarındaki etkilerini ve etki mekanizmalarını da ortaya koymaktadır. Bu şekilde şifalı bitkiler başta olmak üzere birçok medikal bitkinin etkinliği, toksisitesi, etkin konsantrasyonları vb özellikleri açıklanabilmektedir.
Bu makalenin amacı bilimsel popülerliği hızla artan yeşil çayın çocuklarda kullanımının dental ve periodontal sağlığa etkileriyle ilgili güncel literatür bilgilerini derlemektir.

\section{Yeşil Çay}

Çay (Camellia sinesis), yaz, kış her dem yeşil ağaç ya da çalı toplulukları olan Theaceae familyasının alt türüdür. Camellia sinesis (C. sinesis), Hindistan, Çin, Sri Lanka, Japonya, Endonezya, Pakistan, Türkiye, Kenya, Malawi ve Arjantin'de yetiştirilen, çoğunlukla soğuğa dayanıklı yüksek yerlerde ve tropik iklimlerde yetişen bir bitkidir $(2,3)$. C. sinesis'in yapraklarından hazırlanan çaylar, yaprakların işlenme yöntemine veya hasat edilen yaprakların bulundukları gelişim aşamasına göre siyah (fermente edilmiş), yeşil (fermente edilmemiş) ve oolong (yarı fermente edilmiş) çayları olarak farklı türlere ayrılmıştır. Dünya çapında üretilen ve tüketilen çayın yaklaşık $\% 77$ 'si siyah, \%21'i yeşil ve \%2'ye yakını oolong'dur (4).

Yeşil çayın kuru ağırlığının yaklaşık \%20'sini proteinler , \%7'sini karbonhidratlar (selüloz, pektin, glikoz, fruktoz) \%2,5 aminoasitler, ve $\% 5$ 'ini ise mineral ve diğer elementler (yağlar, vitaminler [B,C,E], sterol, ksantik bazlar [kafein, theophylline], pigmentler ve uçucu bileşikler) oluşturmaktadır (5).

Yeşil çay, içerisinde bulunan polifenollerin alt grubu olan flavonoidler özellikle kateşinler ve kateşin türevlerinden zengindir. Yeşil çay, siyah çay ve oolong çayından daha fazla kateşin içerir. Yeşil çay kateşinleri toplam kuru çay ağırlığının yaklaşık \%33'ünü oluşturur. Epigallokateşin gallat (EGCG), epigallokateşin (EGC), epikateşin (EC) ve epikateşin gallat (ECG), yeşil çayda bulunan başlica kateşinlerdir. EGCG antioksidan, antitümörijenik, antienflamatuar ve antianjiyojenik özellikleri nedeniyle oldukça dikkat çekmiştir (6). Ayrıca yeşil çayda en çok bulunan kateşindir (7). EGCG, kateşinler içinde en yüksek antioksidan etkiye sahip bileşiktir (8). 


\section{Yeşil Çayın Genel Să̆lı̆̆a Etkileri}

Yapılan birçok çalışmanın ortak noktası, yeşil çayın sağlığa potansiyel faydalarının çoğunun içeriğindeki polifenollerden kaynaklandığ 1 yönündedir. Hayvan deneyleri, yeşil çay kateşinlerinin dejeneratif hastalıklara karş1 koruyuculuğunu göstermektedir (9).

\section{Çayın başlıca sağlı̆̆a etkileri şu şekilde stralanabilir:}

Antioksidan etkiye sahiptir $(3,10,11)$. Çayın bu etkisi sayesinde çeşitli kardiovasküler hastalıklarda (Örn; ateroskleroz) önleyici özelliği olduğu iddia edilmiştir $(11,12)$. ABD, Avrupa ve Birleşik Krallık'a ait çalışmaları inceleyen bir meta analizde günde üç fincan çay tüketiminin miyokard enfarktüs insidansını \%11 azalttığını bildirmektedir (13).

Antiülseratiftir. Takabayashi ve ark.(14) kemirgenler ile yaptıkları çalışmada yeşil çay kateşinlerinin helicobacter pylori üzerinde inhibitör etkisi olduğu sonucuna varılmıştır. Yeşil çay ve kateşinlerinin helicobacter pylori enfeksiyonlarını azalttı̆̆ını bildiren çalışmalar da vardir $(14,15)$.

Antikarsinojen etkiye sahiptir. Kanser insidansını ve çeşitliliğini etkileye bilirliği, spesifik kanser türlerine ait klinik, epidemiyolojik ve hayvansal çalışmalarla desteklenmiştir (16-20).

Çağımızın en büyük problemlerinden biri olan obezitenin önlenmesinde yeşil çay tüketiminin etkili olduğu bilinmektedir. Düzenli çay tüketimi vücut yă̆ oranını, kolesterol seviyelerini düşürürken aynı zamanda antidiabetik ve antihipertansif etki de göstermektedir (21).

Antimikrobiyal ve antiviral etkileri vardir. Yapılan çalışmalar mikrobiyal ve viral enfeksiyonlarda yeşil çayın hem önleyici hem de tedavi edici potansiyelinin olduğunu göstermiştir (22).

\section{Yeşil Çayın Ăğı Sağlı̆̆ına Etkileri}

Çay katekşinlerinin antimikrobiyal, antioksidan vb. etkileri, yeşil çayın oral sağlık üzerine de etkinliğinin araştırılmasına kaynak olmuştur. Son yıllarda bitkisel/doğal ürünlere artan taleple beraber yeşil çay özütlü gargaralar, macunlar, oral spreyler gibi birçok dental bakım ürünü üretilmiştir.

Diş Çürüğü ve Dental Plak Üzerine Etkisi: Çayın bileşenindeki kateşinler, Streptococcus mutans (S. mutans) bakterileri tarafindan üretilen, sükrozu glukana dönüştüren glukoziltransferaz enzimlerinin aktivitesini inhibe eder. Böylelikle S. mutans tarafindan kolayca fermente edilen karbonhidrat (maltoz) oluşumunu engeller. Dolayısıyla bakteri üremesi ve asit üretimi engellenmiş olur $(23,24)$.

Periodontal Dokularda Etkisi: Çay antimikrobiyal, antioksidan ve antikollogenaz etkileriyle periodontal dokularda iyileştirici özelliğe sahiptir (24-26). Ayrıca EGCG, osteoblastlarda bazı matriks metalloproteinazların ekspresyonunu azaltıp, osteoklast oluşumunu engelleyerek, periodontal hastalığı olan bireylerde alveolar kemik rezorpsiyonunu önleyebilir (26).

Halitozisde Etkisi: Yeşil çayın gargara olarak uzun süre kullanımı ağız kokusuna temelde sebep olan uçucu sülfür bileşiklerinin (VSC) seviyesini azaltır (27). EGCG ve yeşil çay ekstratları VSC üreten gram pozitif anaerobik Solobacterium moorei bakterisini inhibe ederek ve oral epitele yapışmasını engelleyerek ağız kokusunu azaltmaya yardımcı olur (28).

Oral Malignitelede Potansiyel Kemopreventif Etkisi: Yeşil çay ve EGCG sahip oldukları antioksidan, antianjiogenez, , antimikrobiyal aktivite, radyasyonun etkilerini azaltma, apoptozis ve hücre döngüsü regülasyonu özelliklerinin tümü sayesinde kemopreventif etki göstermektedir (29). Squamoz hücreli karsinomlarda yeşil çay ve EGCG'nin kanserli hücreleri inhibe ettiği sonucuna varılmıştır $(30,31)$.

Diş Sert Dokusu Üzerine Koruyucu ve Onarıc1 Etkisi: C. sinensis gibi Theaceae familyasındaki bitkiler, yapraklarında ve infüzyonlarında yüksek konsantrasyonlarda florür içerir (32). Yeşil çay, diş çürüklerini önlemek için topikal florür kaynağı olarak faydalıdır (33).

\section{Yan Etkileri}

Yeşil çay tüketiminin belirgin bir yan etkisi olmamakla beraber çeşitli minerallerin 
metabolizmasinı etkilemesi, hepatotoksisite ve aşırı tüketiminde kafein içeriğine bağlı yan etkilerinden söz edilebilir (34).

Yeşil çay bazı metal iyonlarının emilimini etkileyebilir (35). Uzun süre yeşil çay tüketimi demir emilimini azaltır ve bu durumdan özellikle "hem" olmayan demir etkilenir (36). Çinko emilimini azaltırken magnezyumun emilimini arttırır ve bakır emilimini görünür oranda değiştirmez (37).

Hayvan deneylerinde oral yoldan verilen yeşil çay ekstresinin (\%85 EGCG içeren) median letal dozu yaklaşı $3-5 \mathrm{~g} / \mathrm{kg}^{\prime} \mathrm{d} ı$ ( (38). Yeşil çay ekstraktlarının hepatotoksiteye ilișkin riskleri hala tam olarak netleşmemiştir. 2008-2015 y1lları arasinı kapsayan bir meta analizin sonucunda yeşil çayın tek başına hepatotoksisiteye neden olduğuna dair kesinliğin olmadığı ancak çok yüksek dozlarda ve uzun süre yeşil çay ekstraktlarının kullanımının hepatotoksisite açısından riskli olduğu sonucuna varılmıştır (39).

Avrupa Gıda Güvenliği Otoritesi (EFSA) yayınladığı raporda "geleneksel şekilde hazırlanan yeşil çay infüzyonundan elde edilen kateşinler ve geleneksel yeşil çay infüzyonlarına eşdeğer bir bileşime sahip sulandırılmış içecekler, güvenlik varsayımına göre genel olarak güvenli kabul edilir" ifadeleriyle yeşil çayın tüketim güvenilirliği açıklanmıştır (39).

\section{Çocuklarda Yeşil Çay Kullanımı}

Klorheksidin (CHX) kimyasal etkinliği kanıtlanmış, en yaygın kullanılan antigingivit ve antiplak ajandır. CHX uzun etki süresi sayesinde tükürükteki mikroorganizma sayısını \%90 oranında düşürmektedir. Fakat CHX!in uzun süre kullanımına bağlı olarak ağız dokularını boyama, tat kaybı, diş taşı oluşumu, tek taraflı veya çift taraflı parotis bezi şişmesi, mukozal ülserasyonlar, uzun dönemde oral florada değișim gibi bazı yan etkileri bulunmaktadır (40). C.sinensis, fitokimyasal ve farmakolojik özellikleriyle gargaralarda aktif bileşen olarak kullanılmaya mükemmel bir adaydır (41). Yeşil çayın ideal bir gargara olabileceği yönündeki düşünceler in vivo çalışmalarla da desteklenmiştir (4244).

Yeşil çayla ilgili çocukların katılımcı olduğu çalışmalar çoğunlukla son 5-6 y1l içerisinde yoğunlaşmıştır. Güncel çalışmalara dair bilgiler Tablo 1'de sunulmuştur. İncelenen çalışmaların hiçbirinde kullanımına bağlı yan etkilerden bahsedilmemiştir.

Tablo 1. Çocuklarda yeşil çayla ilgili yapılan çalışmalara ait bilgiler

\begin{tabular}{|c|c|c|c|c|c|}
\hline YAZAR VE YIL & HEDEF & $\begin{array}{l}\text { KULLANILAN } \\
\text { AJANLAR }\end{array}$ & KATILIMCI & $\begin{array}{l}\text { SÜRE- } \\
\text { MIKTAAR }\end{array}$ & SONUÇLAR \\
\hline $\begin{array}{l}\text { Abdülmecid ve } \\
\text { ark./2015(58) }\end{array}$ & $\begin{array}{l}\text { Yeşil çay (Y.Ç) ve bal } \\
\text { solüsyonlarının tükürükteki } \\
\text { Streptococcus mutans } \\
\text { (S.mutans) düzeyi } \\
\text { üzerindeki etkisini } \\
\text { değerlendirmek }\end{array}$ & $\begin{array}{l}\text { Y.Ç } \\
\text { Bal } \\
\text { (gargara) }\end{array}$ & $\begin{array}{l}7-10 \text { yaş } \\
30 \text { çocuk }\end{array}$ & $\begin{array}{l}\text { Tek seferlik } \\
\text { uygulama ( } 2 \mathrm{dk})\end{array}$ & $\begin{array}{l}\text { Bal ve Y. Ç } \\
\text { solüsyonları tükürük S. } \\
\text { mutans sayısını etkili bir } \\
\text { şekilde azalttı }(\mathrm{P}<0.05) \text {. }\end{array}$ \\
\hline $\begin{array}{l}\text { Hambire ve } \\
\text { ark./2015(56) }\end{array}$ & $\begin{array}{l}\text { Y.Ç, sodyum florür }(\mathrm{NaF}) \\
\text { ve Klorheksidin }(\mathrm{CHX}) \\
\text { glukonat gargaralarının } \\
\text { plak önleyici etkinliğini } \\
\text { karşılaştırmak }\end{array}$ & $\begin{array}{l}\% 0.5 \mathrm{Y} . \mathrm{C} \text { ekstresi, } \\
\% 0.05 \mathrm{NaF} \\
\% 0.2 \mathrm{CHX} \text { glukonat } \\
\text { (gargara) }\end{array}$ & $\begin{array}{l}9-14 \text { yaş } \\
60 \text { çocuk }\end{array}$ & $\begin{array}{l}2 \text { hafta } \\
\text { boyunca günde } \\
2 \text { kez (1 dk) }\end{array}$ & $\begin{array}{l}\text { Plak ve diş eti skorları, deney } \\
\text { gruplarında azaldı. } \\
\text { Plak önleyici etkinlik tüm } \\
\text { gruplarda gözlendi, en yüksek } \\
\text { etki Y.Ç grubundaydı (P < } \\
0.05) \text {. } \\
\text { CHX glukonat ve çay, diş eti } \\
\text { skorunda NaF'den daha iyi } \\
\text { etkinlik gösterdi ( }<<0.05) \text {. } \\
\text { Tükürük pH artışı NaF ve } \\
\text { Y.Ç’da CHX'den daha } \\
\text { yüksek ve anlamlıydı. } \\
\text { \%0.5 C. sinensis özütünün } \\
\text { etkinliği, \%0.05 NaF ve \%0.2 } \\
\text { CHX glukonat ağız } \\
\text { gargaralarına kıyasla daha } \\
\text { fazladır. }\end{array}$ \\
\hline
\end{tabular}




\begin{tabular}{|c|c|c|c|c|c|}
\hline $\begin{array}{l}\text { Thomas ve } \\
\text { ark./2016(46) }\end{array}$ & $\begin{array}{l}\text { Y.Ç ve CHX } \\
\text { gargaralarının } \\
\text { antimikrobiyal etkinliğini } \\
\text { S.mutans, Lactobacilli } \\
\text { spp. Ve Candida } \\
\text { Albicans'a karşı } \\
\text { değerlendirmek ve } \\
\text { karşılaştırmak. }\end{array}$ & $\begin{array}{l}\% 0.5 \text { Y.C } \\
\% 0.2 \mathrm{CHX} \\
\text { (gargara) }\end{array}$ & $\begin{array}{l}4-6 \text { yaş } \\
30 \text { çocuk }\end{array}$ & $\begin{array}{l}2 \text { hafta boyunca } \\
\text { günde } 1 \mathrm{kez}\end{array}$ & $\begin{array}{l}\text { S. mutans sayısındaki } \\
\text { azalmada, } \\
\text { Y.Ç >CHX } \\
\text { Lactobacilli spp.'de CHX> } \\
\text { Y. Ç } \\
\text { C. Albicans'a karşı ise } \\
\text { istatistiksel anlamlı fark yok. }\end{array}$ \\
\hline $\begin{array}{l}\text { Ali ve } \\
\text { ark./2019(43) }\end{array}$ & $\begin{array}{l}\text { Y.Çın ağız gargarasının } \\
\text { antimikrobiyal etkinliğini } \\
\text { S. mutans ve Lactobacilli } \\
\text { spp.'ye karşı CHX ile } \\
\text { karşılaştırmak }\end{array}$ & $\begin{array}{l}(\% 0.125) \text { CHX } \\
\text { Renkli su } \\
(\% 0,5) \text { Y.Ç (gargara) }\end{array}$ & $\begin{array}{l}60-71 \text { ay } \\
42 \text { çocuk }\end{array}$ & $\begin{array}{l}2 \text { hafta boyunce } \\
\text { günde } 1 \text { kez }\end{array}$ & $\begin{array}{l}\text { Hem cHX hem de Y. Ç ağız } \\
\text { çalkalama suları, S. mutans } \\
\text { ve Lactobacilli spp. koloni } \\
\text { sayılarında istatistiksel olarak } \\
\text { anlamlı bir düşüş gösterdi . ( } \\
\mathrm{P}<0,001 \text { ve }<0,001 \text { ), }\end{array}$ \\
\hline $\begin{array}{l}\text { Goyalve } \\
\text { ark./2017(49) }\end{array}$ & $\begin{array}{l}\text { Y.Ç kateşininin çocuklarda } \\
\text { koloni sayısı S. mutans } \\
\text { üzerindeki antimikrobiyal } \\
\text { etkinliğini değerlendirmek }\end{array}$ & $\begin{array}{l}\% 0.25 \mathrm{w} / \mathrm{v} \text { kateşin } \\
\text { çözeltisi } \\
\text { (gargara) }\end{array}$ & $\begin{array}{l}7-12 \text { yaş } \\
30 \text { çocuk }\end{array}$ & $\begin{array}{l}2 \text { hafta boyunca } \\
\text { günde } 2 \text { kez }\end{array}$ & $\begin{array}{l}\text { Y. Ç kateşinin } \mathrm{S} \text {. } \\
\text { mutans'a karşı ağız yıkamada } \\
\text { etkili olduğunu }(\mathrm{p}<0,001) \\
\text { ve tükürüğe kıyasla plakta } \\
\text { daha iyi etki. }\end{array}$ \\
\hline $\begin{array}{l}\text { Rahul J Hegde, } \\
\text { Shamika } \\
\text { Kamath/2017(44) }\end{array}$ & $\begin{array}{l}\text { Streptococcus mutans ve } \\
\text { Lactobacillus'un tükürük } \\
\text { sayısını azaltmada CHX ve } \\
\text { kombinasyon (CHX ve } \\
\text { NaF) agargarasının } \\
\text { etkinliğini Y.Ç özütü } \\
(\% 0,5) \text { ile karşılaştırmak } \\
\end{array}$ & $\begin{array}{l}\mathrm{CHX}(\% 0,12) \\
\mathrm{CHX} \text { ve } \mathrm{NaF} \\
\text { Y.Ç özütü }(\% 0,5) \\
\text { (gargara) }\end{array}$ & $\begin{array}{l}8-12 \text { yaş } \\
75 \text { ç }\end{array}$ & $\begin{array}{l}2 \text { hafta boyunca } \\
\text { günde } 1 \text { kere }\end{array}$ & $\begin{array}{l}\text { Üç çalışma grubunun } \\
\text { tümünde S. mutans ve } \\
\text { lactobacilli sayısında } \\
\text { istatistiksel olarak anlamlı bir } \\
\text { azalma var. CHX daha fazla } \\
\text { azalma kombinasyon ve Y. Ç } \\
\text { arasında anlamlı fark yok }\end{array}$ \\
\hline $\begin{array}{l}\text { Kamalaksharappa } \\
\text { ve ark./2018(54) }\end{array}$ & $\begin{array}{l}\text { Probiyotik ve yç } \\
\text { gargaralarının tükürük } \\
\text { ph'sı üzerindeki etkilerinin } \\
\text { değerlendirmek }\end{array}$ & $\begin{array}{l}\text { Probiyotik } \\
\text { Y.Ç } \\
\text { (garagara) }\end{array}$ & $\begin{array}{l}6-8 \text { yaş } \\
40 \text { çocuk }\end{array}$ & $\begin{array}{l}1 \text { ay boyunca } \\
\text { günde } 1 \text { kez }\end{array}$ & $\begin{array}{l}\text { Her iki guruptada ph alkali } \\
\text { yöne doğru artmıştır. }\end{array}$ \\
\hline $\begin{array}{l}\text { Ahmadi ve } \\
\text { ark./2019(59) }\end{array}$ & $\begin{array}{l}\text { Y.Ç jeli ve gargarasının } \\
\text { S.mutans ve } \\
\text { Lactobacillus'un tükürük } \\
\text { seviyesi üzerindeki } \\
\text { etkinliğini karşılaştırmak. }\end{array}$ & $\begin{array}{l}\% 0.5 \text { Y.C gargarası } \\
\text { Jel } \% 0.5 \text { Y.Ç jeli ile } \\
\text { dișlerini firçalamaları } \\
\text { istendi. }\end{array}$ & $\begin{array}{l}12-18 \text { yaş } \\
30 \text { çocuk }\end{array}$ & $\begin{array}{l}2 \text { hafta boyunca } \\
\text { günde iki kez }\end{array}$ & $\begin{array}{l}\text { Y. Ç ağız gargarası ve jelinin, } \\
\text { bir dizi tükürük S. mutans } \\
\text { kolonisinde önemli bir } \\
\text { azalma ile sonuçlandığını } \\
\text { göstermiştir. Y. Ç ağız } \\
\text { gargarası jelden daha } \\
\text { etkiliydi. Ancak aradaki fark } \\
\text { istatistiksel olarak anlamlı } \\
\text { değildi. }\end{array}$ \\
\hline $\begin{array}{l}\text { Salama ve } \\
\text { Alsughier } \\
\text { /2019(50) }\end{array}$ & $\begin{array}{l}\text { Okul öncesi çocuklarda } \\
\text { Y.Ç gargarasının S. } \\
\text { mutans'ın tükürük seviyesi } \\
\text { üzerindeki etkinliğini } \\
\text { değerlendirmek }\end{array}$ & $\begin{array}{l}\text { Y.Ç } \\
\text { (gargara) }\end{array}$ & $\begin{array}{l}4-5 \text { yaş } \\
40 \text { çocuk }\end{array}$ & $\begin{array}{l}\text { 4hafta boyunca } \\
\text { günde } 2 \mathrm{kez}\end{array}$ & $\begin{array}{l}\text { Çalışma grubu, S. } \\
\text { mutans sayılarında kontrol } \\
\text { grubuna göre daha yüksek bir } \\
\text { düşüşs gösterdi . p }<0,001\end{array}$ \\
\hline $\begin{array}{l}\text { Manikandan ve } \\
\text { ark../2020(55) }\end{array}$ & $\begin{array}{l}\text { Probiyotik ve Y.Ç ağız } \\
\text { gargarasının tükürük ph'ı } \\
\text { üzerindeki etkinliğini } \\
\text { değerlendirmek }\end{array}$ & $\begin{array}{l}\text { Probiyotik } \\
\text { Y.Ç } \\
\text { (garagara) }\end{array}$ & $\begin{array}{l}6-8 \text { yaş } \\
40 \text { çocuk }\end{array}$ & $\begin{array}{l}1 \text { ay boyunca } \\
\text { günde } 1 \mathrm{kez}\end{array}$ & $\begin{array}{l}\text { Her iki guruptada ph alkali } \\
\text { yöne doğru artmıştır. }\end{array}$ \\
\hline $\begin{array}{l}\text { Vilela ve } \\
\text { ark../2020(24) }\end{array}$ & $\begin{array}{l}\text { EGCG ve yeşil çayın } \\
\text { (Y.Ç) antimikrobiyal } \\
\text { etkinliğini değerlendirerek } \\
\text { CHX ve distile su ile } \\
\text { karşılaştırmak }\end{array}$ & $\begin{array}{l}4000 \mathrm{Ug} / \mathrm{Ml} \mathrm{EGCG} \\
\text { Yeşil Çay (Y.Ç) } \\
\% 0.12 \text { Alkolsüz CHX } \\
\text { Distile Su } \\
\text { (gargara) }\end{array}$ & $\begin{array}{l}5-12 \\
47 \text { çocuk }\end{array}$ & Tek sefer $(1 \mathrm{dk})$ & $\begin{array}{l}\text { Başlangiçtaki S.mutans } \\
\text { streptokoklar azalma yüzdesi: } \\
\mathrm{CHX}>\text { ECGC }>\text { Y.Ç }>\text { Distile su } \\
\text {.Lactobasillusl azalma } \\
\text { yüzdesi: } \\
\text { EGCG }>\text { Y.Ç }>\text { CHX }>\text { Distile su }\end{array}$ \\
\hline $\begin{array}{l}\text { Deshpande, ve } \\
\text { ark./2021(57) }\end{array}$ & $\begin{array}{l}\text { Y.Ç (YÇ), YÇ artı zencefil } \\
(\mathrm{Y}+\mathrm{Z}) \text { ve } \mathrm{CHX} \\
\text { gargaranın }(\mathrm{CHX}) \\
\text { çocuklarda plak ve diş eti } \\
\text { iltihabı önleyici etkilerini } \\
\text { karşılaştırma }\end{array}$ & $\begin{array}{l}\% 0,2 \text { alkolsüz chx } \\
\% 5 \text { YÇ } \\
\text { YÇ }+Z \\
\text { (gargara) }\end{array}$ & $\begin{array}{l}10-14 \text { yaş } \\
60 \text { çocuk }\end{array}$ & $\begin{array}{l}1 \text { ay boyunca } \\
\text { günde } 2 \mathrm{kez}\end{array}$ & $\begin{array}{l}\text { Y.Ç artı zencefil içeren } \\
\text { gargara, ardından Y.Ç ve } \\
\text { CHX içeren gargara } \\
\text { kullandiktan sonra çocuklarda } \\
\text { plak skoru ve dişeti indeksi } \\
\text { skorunda önemli bir azalma. }\end{array}$ \\
\hline
\end{tabular}




\begin{tabular}{|c|c|c|c|c|c|}
\hline $\begin{array}{l}\text { Ferrazzano/2021 } \\
\text { (48) }\end{array}$ & $\begin{array}{l}\text { Tükürükteki S. mutans ve } \\
\text { Lactobasillus düzeylerini } \\
\text { düşürmede deneysel bir } \\
\text { Y.Ç ekstratının etkinliğini } \\
\text { in vivo olarak test etmekti }\end{array}$ & $\begin{array}{l}\text { Y.Ç ekstresi } \\
\text { Plasebo } \\
\text { (gargara) }\end{array}$ & $\begin{array}{l}12-18 \text { yaş } \\
66 \text { çocuk }\end{array}$ & $\begin{array}{l}\text { haftada üç kez } 1 \\
\text { dakika boyunca }\end{array}$ & $\begin{array}{l}\text { Y. Ç ekstraktının karyojenik } \\
\text { oral floraya karşı etkindir. } \\
\text { Deney grubu, kontrol } \\
\text { grubuna göre S.mutans ve } \\
\text { Lactobasillus koloni } \\
\text { sayılarında istatistiksel olarak } \\
\text { anlamlı bir azalma gösterdi }\end{array}$ \\
\hline $\begin{array}{l}\text { Sajadi ve } \\
\text { ark./2021(47) }\end{array}$ & $\begin{array}{l}\text { CHX, florür ve Y.C’’ın } \\
\text { çocuklarda tükürük S. } \\
\text { mutans ve Lactobacillus } \\
\text { üzerindeki etkilerini } \\
\text { araştırmak } \\
\text { NaF ve Y.Ç ağız }\end{array}$ & $\begin{array}{l}\% 5 \text { Y.Ç jel, } \\
\% 2 \text { CHX jel } \\
\% 0.2 \text { florür jel }\end{array}$ & $\begin{array}{l}4-6 \text { yaş } \\
60 \text { çocuk }\end{array}$ & $\begin{array}{l}\text { Tek seferlik } \\
\text { uygulama ( } 5 \mathrm{dk})\end{array}$ & $\begin{array}{l}\text { Her üç jel tipinin } \\
\text { uygulanmasindan } 1 \text { hf sonra } \\
\text { karyojenik bakterileri } \\
\text { azaltmada Y. Ç ekstresi jeli, } \\
\text { florür ve CHX jele kıyasla } \\
\text { daha uzun süre etkiliydi. }\end{array}$ \\
\hline $\begin{array}{l}\text { Tahrani ve } \\
\text { ark./2021(45) }\end{array}$ & $\begin{array}{l}\text { gargaralarının çocukların } \\
\text { tükürük S. mutans ve } \\
\text { Lactobacillus seviyeleri } \\
\text { üzerindeki etkisini } \\
\text { karşılaştırmak }\end{array}$ & $\begin{array}{l}\% 0.05 \mathrm{NaF} \\
\% 0.5 \mathrm{Y} . \mathrm{C} \\
\text { (gargara) }\end{array}$ & $\begin{array}{l}8-12 \text { yaş } \\
60 \text { çocuk }\end{array}$ & $\begin{array}{l}2 \text { hafta boyunca } \\
\text { günde } 2 \text { kez }\end{array}$ & $\begin{array}{l}\text { Y. Ç ağzı çalkalamanın, } \\
\text { NaFlü ağız çalkalama ile } \\
\text { karşılaştırılabilir tükürük S. } \\
\text { mutans ve Lactobacillus } \\
\text { koloni sayısında önemli bir } \\
\text { azalma ile sonuçlandığını } \\
\text { göstermiştir. }\end{array}$ \\
\hline
\end{tabular}

Yeşil çay gargaralarının sodyum florür $(\mathrm{NaF})$ veya CHX gargaralarıyla karşılaştıııldı $\breve{g}_{1}$ in vivo çalışmalarda S.mutans ve Lactobasillus sayılarında kullanımdan hemen sonra azalma olmuş ve kullanmaya devam ettikçe de azalma devam etmiştir (24,42-48). 2017 y1lında yapılan çalışmada yeşil çay kateşinleriyle hazırlanan gargaranın tükürükteki S. mutans miktarı üzerine olan etkisinin plaktaki S. mutans miktarına olan etkisinden daha fazla olduğu bildirilmiştir $(49,50)$.

CHX'in jel ve gargara formları arasındaki etkinliği karşılaştıran sistematik derlemede jel formunun plak büyümesini bir dereceye kadar engellediğini, ancak gargara formunun daha etkili olduğu sonucuna varmıştır. Yeşil çay jeli ve gargarası arasında benzer bir karşılaştırmayı Ahmedi ve ark.(52) 2019 yılına ait çalışmalarında yapmış ve gargaranın daha etkili olduğunu bildirmiştir.

Çayın Candida Albicans'a karşı etkisini inceleyen birçok çalışma, yeşil çay ve polifenollerinin tükürükteki, biofilmdeki veya akrilik protezlerdeki C. albicans sayısını azalttı̆̆ını söylemiştir (51, 52). Çayın antifungal etkisi; polifenoller tarafindan proteazomal aktivitenin bozulması, biyofilm oluşumunun inhibisyonunu ve hücresel yapı ve metabolizma bozulmasının hızlandırılması olarak açıklanmıştır (53). Dört ila altı yaş arası çocuklara 2 hafta süreyle her gün $1 \mathrm{dk}$ boyunca $5 \mathrm{ml}$ yeşil çay gargarası kullandırılan çalışmada S. mutans ve Lactobasillus sayılarıyla beraber C. albicans miktarında azalma olduğu bildirilmiştir (46).
Yetişkinlerde yapılanların aksine çocuklarda tükürük ve periodontal durum üzerine yapılan çalışmalar oldukça sınırlıdır. Yapılan çalışmalarda tükürük ph'sını alkali yönde arttırdığı(54-56) ve plak ve gingivit önleyici özelliğinin olduğu sonucuna varılmıştır $(56,57)$.

\section{Sonuç}

Yeşil çay ve polifenollerinin antimikrobiyal, antigingivit, antiplak ve antiasit özellikleri çocuklarla yapılan çalışmalarda bir kez daha desteklenmiştir. Yeşil çay, mevcut özellikleriyle, ayrıca; çocuklar tarafindan kabul edilebilir tadı, uygun maliyeti, bilinen yan etkisinin ve belirli bir kullanım süresi olmaması gibi diğer gargaralara karşı avantajlarıyla piyasada bulunan gargaralara ek olarak kullanılabilir. Özellikle erken çocukluk çağı çürüğüne sahip çocuklarda, mental yahut bedensel rahatsızlıkları nedeniyle düzenli firçalama yapamayan çocuk ve yetișkinlerde diş hekimleri tarafindan gargara olarak önerilebilecek güvenli bir ürün olabilir. Tüm bunların yansıra örneklem büyüklüklerinin daha geniş olduğu, konsantrasyon ve dozlarının kar-zarar oranına göre belirlendiği, uzun süreli kullanımına ilişkin sonuçların bulunduğu çalışmalara ihtiyaç vardır.

- 23-25 Kasım, 2021 tarihleri arasında gerçekleşen "Sivas Cumhuriyet Üniversitesi 1.Uluslararası Diş Hekimliği Kongresi" nde online sözlü sunum olarak sunulmuştur 


\section{REFERENCES}

1. Sen T, Samanta SK. Medicinal plants, human health and biodiversity: a broad review. Biotechnological Applications of Biodiversity, 2014;59-110.

2. Spille Gş Caffeine. Chapter 3. Tea: The plant and its manufacture; chemistry and consumption of the beverage. CRC Press. 1997;1-38.

3. Chopade V, Phatak A, Upaganlawar A, et al. Green tea (Camellia sinensis): Chemistry, traditional, medicinal uses and its pharmacological activities-a review. Pharmacognosy Reviews. 2008;2:157.

4. McKay DL, Blumberg JB. The role of tea in human health: an update. $J$ Am Coll Nutr. 2002;21:1-13.

5. Chacko SM, Thambi PT, Kuttan R, et aI. Beneficial effects of green tea: a literature review. Chin Med. 2010;5:13.

6. de Pace RC, Liu X, Sun M, et al. Anticancer activities of (-)-epigallocatechin-3-gallate encapsulated nanoliposomes in MCF7 breast cancer cells. J Liposome Res. 2013;23:187-96.

7. Basu A, Lucas EA. Mechanisms and effects of green tea on cardiovascular health. Nutr Rev. 2007;65:361-75.

8. Nanjo F, Mori M, Goto K, et al. Radical scavenging activity of tea catechins and their related compounds. Biosci Biotech Bioch. 1999;63:1621-3.

9. Belobrov S, Seers C, Reynolds E, et al. Functional and molecular effects of a green tea constituent on oral cancer cells. J Oral Pathol Med. 2019;48:604-10.

10. Crespy V, Williamson G. A review of the health effects of green tea catechins in in vivo animal models. J Nutr. 2004;134:3431-40.

11. Khan N, Mukhtar H. Tea polyphenols for health promotion. Life Sci. 2007;81:519-33.

12. Sasazuki S, Kodama H, Yoshimasu K, et al. Relation between green tea consumption and the severity of coronary atherosclerosis among Japanese men and women. Annals of Epidemiology. 2000;10:401-8.

13. Peters U, Poole C, Arab L. et al. Affect Cardiovascular Disease? A Meta-Analysis. American Journal of Epidemiology. 2001;154:495-503.

14. Yee YK, Koo MW. Anti-Helicobacter pylori activity of Chinese tea: in vitro study. Aliment Pharmacol Ther. 2000;14(5):635-8.

15. Yee YK, Koo MW, Szeto ML. Chinese tea consumption and lower risk of Helicobacter infection. $J$ Gastroenterol Hepatol. 2002;17:552-5.

16. $\mathrm{Gu} \mathrm{Q}, \mathrm{Hu} \mathrm{C}, \mathrm{Chen} \mathrm{Q}$, et al. Development of a rat model by 3, 4-benzopyrene intrapulmonary injection and evaluation of the effect of green tea drinking on p53 and bcl-2 expression in lung carcinoma. Cancer Detection Prevention. 2009;32:444-51.
17. Butt MS, Ahmad RS, Sultan MT,et al. Green tea and anticancer perspectives: updates from last decade. Crit Rev Food Sci Nutr. 2015;55:792-805.

18. Thangapazham RL, Singh AK, Sharma A, et al. Green tea polyphenols and its constituent epigallocatechin gallate inhibits proliferation of human breast cancer cells in vitro and in vivo. Cancer Lett. 2007;245:232-41.

19. Henning SM, Wang $P$, Said $J$, et al. Polyphenols in brewed green tea inhibit prostate tumor xenograft growth by localizing to the tumor and decreasing oxidative stress and angiogenesis. $J$ Nutr Biochem. 2012;23:1537-42.

20. Kanwar J, Taskeen M, Mohammad I, et al. Recent advances on tea polyphenols. Frontiers in Bioscience. 2012;4:111.

21. Nagao T, Hase T, Tokimitsu I. A green tea extract high in catechins reduces body fat and cardiovascular risks in humans. Obesity (Silver Spring). 2007;15:1473-83.

22. Reygaert WC. The antimicrobial possibilities of green tea. Front Microbiol. 2014;5:434.

23. Armidin RP, Yanti GN. Effectiveness of rinsing black tea compared to green tea in decreasing streptococcus mutans. Open Access Maced J Med Sci. 2019;7:3799-802.

24. Vilela MM, Salvador SL, Teixeira IGL, Det al. Efficacy of green tea and its extract, epigallocatechin-3-gallate, in the reduction of cariogenic microbiota in children: A randomized clinical trial. Arch Oral Biol. 2020;114:104727.

25. Sarin S, Marya C, Nagpal R, et al. Preliminary clinical evidence of the antiplaque, antigingivitis efficacy of a mouthwash containing $2 \%$ green tea - a randomised clinical trial. Oral Health \& Preventive Dentistry. 2015;13:197-203.

26. Yun JH, Pang EK, Kim CS, et al. Inhibitory effects of green tea polyphenol (-)epigallocatechin gallate on the expression of matrix metalloproteinase-9 and on the formation of osteoclasts. $J$ Periodontal Res. 2004;39:300-7.

27. Rassameemasmaung $S$, Phusudsawang $P$, Sangalungkarn V. Effect of green tea mouthwash on oral malodor. ISRN Prev Med [Internet]. 2013 2013; 2013:[975148 p.].

28. Morin MP, Bedran TB, Fournier-Larente J, et al. Green tea extract and its major constituent epigallocatechin-3-gallate inhibit growth and halitosis-related properties of Solobacterium moorei. BMC Complement Altern Med. 2015;15:48.

29. Carlson JR, Bauer BA, Vincent A, et al. Reading the tea leaves: anticarcinogenic properties of (-)-epigallocatechin-3-gallate. Mayo Clin Proc. 2007;82:725-32. 
30. Elattar T, Virji AS. Effect of tea polyphenols on growth of oral squamous carcinoma cells in vitro. Anticancer Research. 2000;20:3459-65.

31. Irimie $\mathrm{AI}$, Braicu $\mathrm{C}$, Zanoaga $\mathrm{O}$, et al. Epigallocatechin-3-gallate suppresses cell proliferation and promotes apoptosis and autophagy in oral cancer SSC-4 cells. Oncotargets and Therapy. 2015;8:461.

32. Malinowska E, Inkielewicz I, Czarnowski W, et al. Assessment of fluoride concentration and daily intake by human from tea and herbal infusions. Food Chem Toxicol. 2008;46:105561.

33. Suyama E, Tamura $T$, Ozawa $T$,et al. Remineralization and acid resistance of enamel lesions after chewing gum containing fluoride extracted from green tea. Australian Dental Journal. 2011;56:394-400.

34. Schonthal AH. Adverse effects of concentrated green tea extracts. Mol Nutr Food Res. 2011;55:874-85.

35. Mira L, Fernandez MT, Santos M, et al. Interactions of flavonoids with iron and copper ions: a mechanism for their antioxidant activity. Free Radical Res. 2002;36:1199-208.

36. Samman S, Sandstrom B, Toft MB, et al. Green tea or rosemary extract added to foods reduces nonheme-iron absorption. Am J Clin Nutr. 2001;73:607-12.

37. Zeyuan D, Bingying T, Xiaolin L, et al. Effect of green tea and black tea on the metabolisms of mineral elements in old rats. Biol Trace Elem Res. 1998;65:75-86.

38. Yamane $\mathrm{T}$, Nakatani $\mathrm{H}$, Kikuoka $\mathrm{N}$, et al. Inhibitory effects and toxicity of green tea polyphenols for gastrointestinal carcinogenesis. Cancer. 1996;77:1662-7.

39. Mazzanti G, Di Sotto A, Vitalone A. Hepatotoxicity of green tea: an update. Arch Toxicol. 2015;89(8):1175-91.

40. Addy M. Chlorhexidine compared with other locally delivered antimicrobials. A short review. J Clin Periodontol. 1986;13:957-64.

41. Moghbel A, Farajzadeh A, Aghel N, et al. Formulation and evaluation of green tea mouthwash: A new, safe and nontoxic product for children and pregnant women. Toxicology Letters. 2009;189:S257-S.

42. Karim B, Bhaskar DJ, Agali C, et al. Effect of Aloe vera mouthwash on periodontal health: triple blind randomized control trial. Oral Health Dental Management. 2014;13:14-9.

43. Ali AMM, Ahmed WH, Abd El-Baky RM,et al. Antibacterial efficacy of green tea mouth rinse in children with early childhood caries. Tanta Dental Journal. 2019;16:6.

44. Hegde RJ, Kamath S. Comparison of the Streptococcus mutans and Lactobacillus colony count changes in saliva following chlorhexidine $(0.12 \%)$ mouth rinse, combination mouth rinse, and green tea extract $(0.5 \%)$ mouth rinse in children. Journal of the Indian Society of Pedodontics and Preventive Dentistry. 2017;35:150-5.
45. Tehrani MH, Asghari G, Hajiahmadi M. Comparing Streptococcus mutans and Lactobacillus colony count changes following green tea mouth rinse or sodium fluoride mouth rinse use in children (Randomized double-blind controlled clinical trial). Dental Research Journal. 2011;8S58.

46. Thomas A, Thakur SR, Shetty SB. Antimicrobial efficacy of green tea and chlorhexidine mouth rinses against Streptococcus mutans, Lactobacilli spp. and Candida albicans in children with severe early childhood caries: A randomized clinical study. Journal of the Indian Society of Pedodontics and Preventive Dentistry. 2016;34:65-70.

47. Sajadi FS, Rostamizadeh M, Hasheminejad J, et al. Effect of Chlorhexidine, Fluoride and Green Tea Oral Gel on Pediatric Salivary Cariogenic Bacteria: A Clinical Trial Study. Int J Pediatr-Massha. 2021;9:13947-56.

48. Ferrazzano GF, Roberto L, Amato I, et al. Antimicrobial properties of green tea extract against cariogenic microflora: an in vivo study. J Med Food. 2011;14:907-11.

49. Goyal AK, Bhat M, Sharma M, et al. Effect of green tea mouth rinse on Streptococcus mutans in plaque and saliva in children: An in vivo study. Journal of Indian Society of Pedodontics Preventive Dentistry. 2017;35:41.

50. Salama MT, Alsughier ZA. Effect of Green Tea Extract Mouthwash on Salivary Streptococcus mutans Counts in a Group of Preschool Children: An In Vivo Study. International Journal of Clinical Pediatric Dentistry. 2019;12:133-8.

51. Antunes DP, Salvia ACRD, de Araújo RM, et al. Effect of green tea extract and mouthwash without alcohol on Candida albicans biofilm on acrylic resin. Gerodontology. 2015;32:2915.

52. Tafazoli A, Tafazoli Moghadam E. Camellia Sinensis mouthwashes in oral care: a systematic review. Journal of Dentistry (Shiraz, Iran). 2020;21:249-62.

53. Evensen NA, Braun PC. The effects of tea polyphenols on Candida albicans: inhibition of biofilm formation and proteasome inactivation. Can J Microbiol. 2009;55:10339.

54. Kamalaksharappa SK, Rai R, Babaji P, et al. Efficacy of probiotic and green tea mouthrinse on salivary $\mathrm{pH}$. Journal of the Indian Society of Pedodontics and Preventive Dentistry. 2018;36:279-82.

55. Manikandan S, Behera S, Karthikeyan R, et al. Effect of green tea extract mouthrinse and probiotic mouthrinse on salivary ph in a group of schoolchildren: An in vivo study. $J$ Pharm Bioallied Sci. 2020;12(Suppl 1):S404-S9.

56. Hambire $\mathrm{CU}$, Jawade $\mathrm{R}$, Patil $\mathrm{A}$, et al. Comparing the antiplaque efficacy of $0.5 \%$ Camellia sinensis extract, $0.05 \%$ sodium fluoride, and $0.2 \%$ chlorhexidine gluconate 
mouthwash in children. $J$ Int Soc Prev Community Dent. 2015;5:218-26.

57. Deshpande A, Deshpande N, Raol R, et al. Effect of green tea, ginger plus green tea, and chlorhexidine mouthwash on plaque-induced gingivitis: A randomized clinical trial. $J$ Indian Soc Periodontol. 2021;25:307-12.

58. Abdelmegid F, Al-Agamy M, Alwohaibi A, et al. Effect of honey and green tea solutions on Streptococcus mutans. J Clin Pediatr Dent. 2015;39:435-41.

59. Ahmadi MH, Sarrami L, Yegdaneh A, et al. Comparative evaluation of efficacy of green tea mouth rinse and green tea gel on the salivary Streptococcus mutans and Lactobacillus colony count in 12-18-year-old teenagers: A randomized clinical trial. Contemporary Clinical Dentistry. 2019;10:815. 